\title{
Reforma do Ensino Médio no Brasil e crise mundial da educação: uma análise reflexiva da flexibilização das humanidades na educação básica
}

\author{
Altair Alberto Fávero ${ }^{1}$ \\ Daiane Rodrigues Costa ${ }^{2}$ \\ Junior Bufon Centenaro ${ }^{3}$
}

\begin{abstract}
RESUMO
O presente artigo discute a reforma do ensino médio no Brasil (lei 13.415/2017) tendo por escopo apontar suas limitações na medida em que negligencia aspectos básicos para a formação humana, integral e democrática ao assumir um viés mercantilista e tecnicista. Para isso, nos baseamos nas reflexões de Martha Nussbaum, que aponta os riscos que os países estão correndo ao priorizar apenas aspectos lucrativos na educação dos cidadãos. Nosso estudo busca responder satisfatoriamente a seguinte pergunta: em que medida o novo ensino médio representa uma guinada para um viés mercantilista da educação? Amparados em pesquisa bibliográfica e documental, de caráter analítico-hermenêutico, temos como hipótese de que o "novo ensino médio", ao relativizar as artes e as humanidades, entre elas a filosofia, fragiliza o processo de formação integral do sujeito.
\end{abstract}

PALAVRAS-CHAVE: Flexibilização. Ensino Médio. Humanidades. Nussbaum.

Reform of Secondary School in Brazil and the world crisis of education: a reflexive analysis about the flexibilization of the humanities in basic education

\footnotetext{
${ }^{1}$ Doutor. Universidade de Passo Fundo (UPF), Passo Fundo, RS, Brasil. http://orcid.org/0000-0002-9187-7283. altairfavero@gmail.com.

2 Mestrando em Educação. Universidade de Passo Fundo (UPF), Passo Fundo, RS, Brasil. http://orcid.org/00000003-2007-2303.142947@upf.br.

${ }^{3}$ Mestrando em Educação. Universidade de Passo Fundo (UPF), Passo Fundo, RS, Brasil. http://orcid.org/00000003-3046-3885.junior.centenaro@bol.com.br.
} 


\begin{abstract}
The present article discusses the reform of secondary education in Brazil (Law 13.415 / 2017), whose scope is to point out its limitations insofar as it neglects basic aspects of human, integral and democratic formation by assuming a mercantilist and technicist bias. For this, we base ourselves on the reflections of Martha Nussbaum, who points out the risks that the countries are running when prioritizing only lucrative aspects in the education of the citizens. Our study seeks to answer the following question satisfactorily: to what extent does the new secondary school represent a turning point for a mercantilist bias in education? Based on bibliographical and documentary research, with an analyticalhermeneutical character, we hypothesize that the "new secondary school", by relativizing the arts and humanities, among them philosophy, weakens the process of integral formation of the subject.
\end{abstract}

KEYWORDS: Flexibilization; Secondary School; Humanities;

Nussbaum.

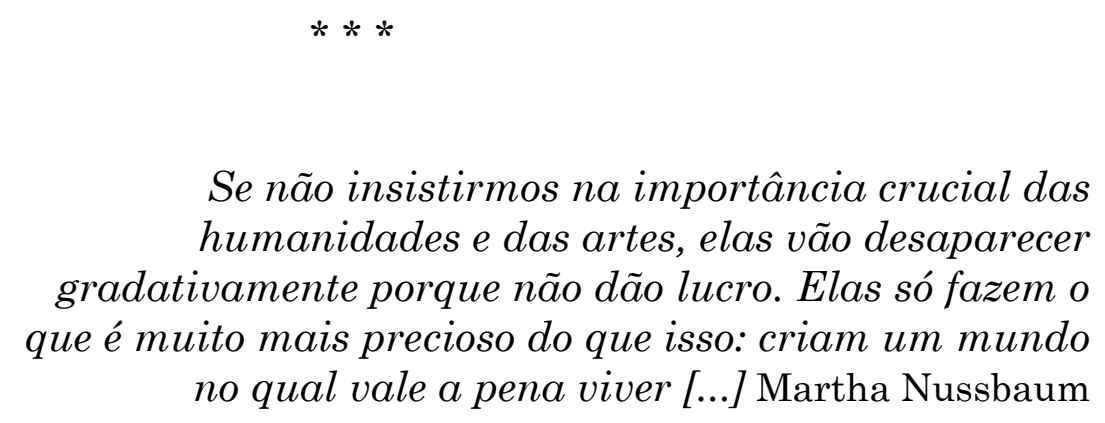

\title{
Introdução
}

O trabalho proposto tem como objetivo contextualizar a reforma do ensino médio brasileiro no conjunto da crise mundial da educação, que está assentada segundo Martha Nussbaum (2005, 2014, 2015), na gradativa ausência e retirada do ensino das humanidades e das artes. Analisar a reforma no ensino médio à luz de tal referencial teórico, nos permite perceber o que está sendo colocado em jogo pelas novas diretrizes, não somente para o ensino médio, mas para a educação básica brasileira como um todo. 
Buscamos com este estudo elucidar uma resposta satisfatória para a pergunta: em que medida o novo ensino médio representa uma guinada para um viés mercantilista da educação? Para tanto, em relação a abordagem do problema, realizamos uma pesquisa qualitativa. Quanto aos procedimentos do estudo, nosso movimento foi orientado por pesquisa bibliográfica e documental. Uma leitura hermenêutica da bibliografia básica proporcionou uma apropriação conceitual do ideal de educação de Nussbaum. A pesquisa documental possibilitou compreender as convergências e divergências entre o referencial teórico e a legislação que estabeleceu mudanças para o ensino médio.

Para um melhor entendimento, o presente texto foi em três partes. Inicialmente, reconstruímos a argumentação de Nussbaum (2005, 2014, 2015), que destaca três pilares de sustentação da democracia, que estão vinculados ao ensino das humanidades e das artes, bem como a ideia de que o crescimento de um país, uma sociedade, de uma nação é muito superficial quando mensurado apenas pelo Produto Interno Bruto (PIB), pois existem outros aspectos a serem contemplados. Após essa breve reconstrução de nosso referencial teórico, procuramos expor as principais mudanças provocadas pela lei $\mathrm{n}^{0} 13.415 / 2017$ que estruturou o chamado "novo ensino médio", bem como os principais argumentos pela urgência da reforma evocados pelos seus defensores. Por último, defendemos que os rumos apontados pela nova legislação negligenciam aspectos essenciais para a formação humana, integral e democrática dos jovens brasileiros.

\section{A centralidade do ensino das humanidades para o fortalecimento das relações democráticas}

Martha Nussbaum (2015) defende que inúmeros países vivem uma crise silenciosa da educação. Isso ocorre porque as reformas dos governos que impactam o ensino fundamental, médio e superior consistem na diminuição ou até mesmo na eliminação dos currículos escolares e 
universitários importantes disciplinas das ciências humanas e das artes. Por sua vez, o ensino técnico acaba por ocupar o espaço que corresponderia as humanidades, sendo uma área cada vez mais valorizada. Sem um ensino amplo, a formação humana e cidadã é colocada em risco, pois pressupõe a perda do estímulo ao exercício crítico, criativo, de reconhecer a si e ao outro como um ser humano complexo, multifacetado e com história. Esses elementos, de primeira necessidade às relações democráticas, são cada vez mais suprimidos por um ensino cada vez mais prático e técnico. Conclui a autora que essa forma de ensino, voltado ao mercado de trabalho, financeiro, econômico e dedicado aos lucros, fomenta uma geração de indivíduos que não mais entendem uns aos outros enquanto pessoas, mas como objetos que podem ou não renderem lucros.

Isso ocorre, segundo a autora, porque o Produto Interno Bruto é visto como o único sinônimo de desenvolvimento de um país. Entretanto, como alerta Nussbaum (2015), a soma do PIB não pode representar o desenvolvimento pleno de uma nação, pois a arrecadação de riqueza não significa que esses valores sejam distribuídos de forma justa entre os cidadãos. Essa forma de medir o desenvolvimento negligencia inúmeras outras questões que afetam diretamente o bem viver, como a luta contra a desigualdade de classe, gênero e raça; o acesso de toda população à educação e assistência à saúde de qualidade, entre outros. Nesse sentido, como a meta é aumentar o Produto Interno Bruto, alguns países investem excessivamente nas áreas técnicas das escolas e universidades ao reduzirem o investimento no ensino e pesquisa na área das Ciências Humanas. Assim, as disciplinas obrigatórias relacionadas a essas áreas sofrem cada vez mais pressão pela sua diminuição ou exclusão.

Segundo Flickinger (2009), a atual educação encontra-se dentro do contexto de uma sociedade capitalista do trabalho. Por isso, a inserção dos sujeitos no mercado de trabalho se faz necessária tanto para sua própria subsistência, quanto para seu reconhecimento social. Muitas instituições de ensino, por sua vez, têm como principal objetivo a qualificação técnica dos 
estudantes, visto ser este um requisito de grande valor para o progresso científico e tecnológico do meio. Quem define, portanto, quais as profissões e qual o tipo de "instrução" que as instituições de educação devem dar primazia é o próprio mercado. Nesse sentido, o trabalho não possui mais a característica de desenvolver e realizar o ser humano, pois este não se reconhece mais no mesmo. $\mathrm{O}$ sujeito pode optar por um determinado tipo de curso segundo a remuneração ou status social que dele advém. Por isso, Flickinger (2009) aponta que esse sistema simplesmente torna remota a possibilidade do sujeito construir sua própria biografia, pois, ao invés de escolher uma formação e profissão que o realize, ele opta por escolher aquilo que garantirá mais sua sobrevivência no mundo. Assim:

Não é o homem cujas vontades e aspirações condicionam o processo de sua formação; pelo contrário, ele se vê tratado como que um apêndice de um mundo regido pela lógica meramente material, pois não consegue influenciar substancialmente as regras gerais do jogo do qual tem de fazer parte, nem os pilares de seu destino e a projeção de sua biografia futura (FLICKINGER, 2009, p. 74).

Não é intenção da autora defender e nem a nossa em ratificar que o ensino técnico não se faz necessário. A profissionalização possui um papel importante para o desenvolvimento da sociedade e do indivíduo. No entanto, a educação não pode ser restringida a isso. É preciso considerar que existem outros aspectos humanos a serem formados além da instrução técnica de um saber manual. Segundo Dalbosco (2015), Rousseau, já no século XVIII, havia constatado que o desenvolvimento técnico-científico de uma sociedade não tem como resultado necessário o melhoramento moral da mesma. Isto é, as relações humanas não tornam-se mais saudáveis devido ao crescimento técnico, econômico ou do mercado de trabalho, pois nas palavras do autor, "a ciência só se torna realmente emancipadora quando associada a processos dialógicos, solidários e cooperativos" (DALBOSCO, 2015, p. 124). Essa 
supervalorização da educação técnica, negligenciaria uma educação cultural mais ampla, como a que foi pensada no contexto da Paidéia grega e na Bildung alemã, onde preservava-se a equidade da formação física, intelectual e emocional. Assim, a formação desenvolve "o ser humano na sua íntegra, não somente como elemento funcional num sistema por ele vivido como um mundo e a ele impingido" (FLICKINGER, 2009, p. 79).

Com a diminuição da presença das humanidades e das artes no currículo acadêmico, a educação começa a voltar-se massivamente para o crescimento econômico. Nussbaum (2015) destaca algumas características dessa forma de ensino e concepção de educação. Primeiramente, prioriza-se a alfabetização e as regras básicas de aritmética. Trabalha-se com noções de informática e tecnologia. Isso porque, segundo essa lógica, nem todas as pessoas necessitam ter amplo acesso à educação, pois pode-se educar um seleto grupo de pessoas que lidera o desenvolvimento tecnológico, sendo peças fundamentais para o acumulo de riqueza, enquanto a maior parte da população permanece com o mínimo possível de acesso ao conhecimento. Para essa parte da população, segundo essa concepção, o ensino de história, política, sociologia, filosofia entre outros, deve ser rudimentar. A pequena elite que tem acesso à educação pode saber e refletir sobre a disparidade salarial entre homens e mulheres, a violência de gênero que leva a morte de muitos homossexuais e mulheres todos os dias, dos sistemas de exploração de uma classe que vive do trabalho; porém um trabalhador comum que possui as condições de pensar sobre esses assuntos pode tornar-se perigoso e colocar em risco a elite que detém o poder econômico.

Por isso, Nussbaum (2015) sugere que esse sistema excludente seja substituído pelo paradigma de desenvolvimento humano, que considera tão importante quanto a arrecadação de riquezas, a sua justa distribuição. Além disso, fornece as oportunidades para que cada indivíduo possa se desenvolver com acesso à educação; liberdade de pensamento, religião e gênero; assistência à saúde, saneamento básico, espaços de cultura e lazer. O ensino de humanidades e das artes é crucial para a promoção dessa forma 
de desenvolvimento, uma vez que elas fortalecem a capacidade de debater diversos assuntos que afetam a complexidade do humano, de julgar criticamente, de pensar o bem estar do coletivo e não apenas do indivíduo, de ver as outras pessoas como fim em si mesmos e não como meios a serem utilizados e descartados, de pensar e sentirem-se comprometidos com a solução de problemas globais.

Os seres humanos, segundo Nussbaum (2015) possuem uma tendência à estabelecerem relações hierárquicas, autoritárias e de violência entre si caso não sejam formados com valores democráticos de vida. É preciso, por isso, entender as forças humanas que se voltam ao respeito e à alteridade e as forças que conduzem às relações de dominação. Para explicar isso, Nussbaum (2015) recorre a condição biológica e psíquica da qual o ser humano é formado. Isso o coloca entre a impotência e a capacidade. Comparados fisicamente com muitos outros animais, qualquer indivíduo tornar-se incapaz de defender-se. Entretanto, a sua capacidade cognitiva é desconhecida para o restante da natureza. O ser humano vive oscilando entre a vulnerabilidade e seu poder cognitivo. Porém, ainda como bebê, ele percebe que não pode ter tudo o que deseja. Surge daí uma lacuna que é preenchida pelo medo e a vergonha de ser o que é. Isso, somado ao desenvolvimento do sentimento de aversão a tudo que pode ser visto como contaminação, surge a repugnância de todos os elementos que lembram a vulnerabilidade humana. Em muitos casos, por conseguinte, esses elementos são identificados em certos indivíduos ou grupos de pessoas, nas quais são projetados todos os tipos de exclusões, preconceitos e violência de inúmeras formas.

Nesse sentido, como a escola, pelo ensino das humanidades e das artes, pode contribuir para mudar a lógica de relações dominadoras? Alguns exercícios são apontados pela autora como colocar-se no ponto de vista do outro, desafiar o uso da autoridade, ser responsabilizado pelas suas ações, comunicar sua opinião, mesmo sendo discordante dos demais, e saber respeitar aquele que é diferente. Para desenvolver isso, Nussbaum (2015) 
acredita ser crucial três pilares na formação de crianças e jovens - a pedagogia socrática, o pensamento cosmopolita e o cultivo da imaginação por meio da arte.

Sócrates, filósofo grego, pertence a uma tradição de filósofos orais que não tinham o costume de deixar textos escritos. Seus diálogos foram registrados pelo seu maior discípulo, Platão. Neles, encontram-se diálogos do filósofo com várias pessoas e sobre os mais variados temas como a origem do conhecimento, sobre a definição do conceito de justiça ou do belo, entre outros. Independente dos assuntos que Sócrates abordava, seu método com os interlocutores era sempre o mesmo. O diálogo segue como um "bumerangue" de perguntas e respostas. A cada resposta dada pelo interlocutor, Sócrates encontra alguma falha na estrutura da argumentação e esse, por sua vez, necessita reformular o argumento, para ser mais uma vez desestruturado pelo filósofo grego. Assim, "por não ser exclusivamente estratégica, tal racionalidade não se concentra exclusivamente no fim a ser alcançado, mas sim no caminho que é construído e refeito pelo próprio diálogo" (DALBOSCO, 2015), uma vez que geralmente os diálogos socráticos não apresentam uma resposta final sobre que foi tratado. Por isso, o que fica como marca principal da pedagogia socrática é o processo de autorreflexão sobre o próprio pensamento e atitudes.

Nussbaum (2015) aponta alguns motivos pelos quais a democracia necessita do debate socrático. Primeiramente, sem debate todos os "votantes" chegam a objetivos pouco claros. Pessoas que não refletem são facilmente influenciadas tanto por emoções superficiais como por autoridades alheias. $\mathrm{O}$ debate permite que as pessoas avaliem o desempenho argumentativo uma das outras e não suas diferenças pessoais. Mesmo que o ensino vise apenas o mercado de trabalho, os ideais socráticos ainda se fazem necessários, pois para que haja inovação é preciso pessoas com alto teor crítico e criativo e não apenas aqueles trabalhadores que se submetem a autoridades dos chefes. Além disso, o pensamento socrático permite "[...] trocar ideias com os outros [pessoas] numa atmosfera racional de respeito 
mútuo, o que é fundamental para a resolução pacífica de divergências tanto no contexto de um só país como no de um mundo que cada vez mais se vai polarizando devido a conflitos étnicos e religiosos" (NUSSBAUM, 2014, p. $79)$.

A autora ainda percorre a obra de grandes pensadores da educação que desenvolveram e colocaram em prática o ideal socrático. Rousseau, Pestalozzi, Froebel, John Dewey, Tagore e Lipman. Todos esses grandes pedagogos desenvolveram ideias próprias de como deve ser a formação de um ser humano. No entanto, todos tinham em comum a concepção de que uma formação não consiste no estudante, passivo, que "recebe" conteúdos dados pelo professor. A aprendizagem não pode ser depositada em um aluno como se este fosse apenas um receptáculo vazio esperando o conhecimento. Ela deve ser construída mediante as experiências que as crianças e os jovens desenvolvem com o mundo, bem como as reflexões que surgem das mesmas. Por isso, em outra obra, (2005), Nussbaum aponta que, com a pedagogia socrática, os estudantes percebem que a filosofia não se trata de uma disciplina abstrata. Além de cognitiva, ela também possui um viés prático, no sentido de nos fazer questionar as determinações que nos são impostas via autoridade alheia, e isso tende sempre a desequilibrar os pilares que sustem os costumes culturais.

Enquanto defensora do pensamento cosmopolita, da necessidade de reconhecer-se como cidadão do mundo, Nussbaum (2015) aponta que os grandes problemas enfrentados no mundo como a crise do meio ambiente, a economia, o tráfico humano, entre outros, só podem ser solucionados mediante uma mobilização global e não individual. Os filósofos estoicos já consideravam que o indivíduo possuía uma dupla cidadania. A primeira, dizia respeito a comunidade em que o sujeito foi educado; e a segunda, a uma cidadania global, da qual deveriam ser pensados os valores éticos, morais e políticos (NUSSBAUM, 2005).

Necessita-se expor que as ações de cada indivíduo possuem impacto para muitas pessoas. No entanto, os ambientes formais de educação, como a 
escola, preparando os estudantes para o mercado de trabalho ou para as provas padronizadas que dão acesso ao ensino superior, fomentam a concorrência entre os estudantes, formando adultos capazes de tratar uns aos outros apenas como objetos de uso, que são facilmente descartáveis. Por isso, se faz necessário que a escola seja um espaço de acesso a diferentes grupos culturais, religiosos, étnicos. Será muito mais tangível que as crianças e os jovens se preocupem com as condições de vida do outro, mesmo sendo esse "outro" muito diferente de si, pois entendem que o mundo é plural e que não existe uma forma de vida padrão e superior as outras. Isso possibilitaria que os indivíduos entendessem o que de suas práticas advém da cultura em que estão inseridos e o que é natural, comum a todos os seres humanos, visto que muitas pessoas confundem natureza com cultura (NUSSBAUM, 2005). Em outra obra, a autora (NUSSBAUM, 2014) defende que a ignorância a respeito de outras culturas é a origem do julgamento que acredita que existe um modo único, natural e inevitável de agir e ser no mundo. Dessa forma, poderemos romper com os [...] resquícios de nosso euro centrismo assentados no fato de sermos varões, brancos, descendentes de europeus, considerados como povo eleito que tem a missão de colonizar a região, o país e o globo" (DALBOSCO, 2015, p. 137).

Em conjunto da racionalidade da argumentação e o conhecimento do diferente, Nussbaum (2015) também aponta ser necessário, para formar cidadãos democráticos, o cultivo da imaginação. A autora recorre a psicologia de Winnicott para mostrar que toda criança, a princípio, não se reconhece diferente do meio. Isso significa, que ela entende que as pessoas que estão a sua volta são apenas uma extensão de seu próprio “eu”. Isso faz com que ela naturalmente tente dominar e submeter o outro aos seus próprios desejos. A brincadeira, nesse caso, pode paulatinamente libertar a criança do desejo de imperar sobre outro. Embora no começo ela tende sempre a querer comandá-la, dizendo o que cada um deve fazer, com o tempo ela passa a entregar-se a surpresa do inesperado e a aceitar a vulnerabilidade que é não estar sempre no controle. Nesse caso, imaginar o 
seu próprio personagem faz com que a criança possa experimentar um outro, o diferente. Além disso, faz com que a vulnerabilidade, causa do desejo de colonizar e dominar, torne-se algo curioso e divertido. Assim, "a imaginação permite ter uma percepção profunda da experiência de outra pessoa que, de outra forma, é muito difícil alcançar na vida quotidiana, sobretudo num mundo em que qualquer encontro é dificultado pelas gigantescas divisões que nele foram criadas" (NUSSBAUM, 2014, p. 81).

Quando adultos, o cultivo da imaginação ocorre por meio das mais variadas expressões artísticas. Porque criar e inventar uma história, por exemplo, exige que o sujeito imagine alguém que não seja ele mesmo, mas um outro com um mundo interior próprio. Uma vez que tudo que está fora do sujeito requer o uso da imaginação para ser entendido. Ela (a imaginação) assume um estreito compromisso com a ética. Entender a perspectiva do "outro", princípio ético basilar, reivindica que o sujeito tenha uma capacidade imaginativa bem desenvolvida. Por isso, Nussbaum (2015) aponta o desenvolvimento do lúdico como um dos pilares para a democracia, pois através de seu desenvolvimento, é possível estabelecer relações humanas que não sejam alicerçadas no domínio, mas na compreensão daquele que é diferente e possui um mundo interior próprio.

Evidenciamos até aqui, na esteira de Nussbaum, que o ensino das humanidades e das artes é de fundamental importância para a formação humana do sujeito e para as relações democráticas. Diante disso, dirigimonos à uma análise da reforma do ensino médio (lei $\mathrm{n}^{0}$ 13.415/2017), que instaurou mudanças estruturais e curriculares para esta etapa da educação formal. Destacaremos de forma descritiva algumas mudanças ocasionadas, de modo especial com relação aos ensino das humanidades e na sequência faremos uma análise crítica desses elementos a partir do referencial teórico do qual nos apropriamos na primeira parte deste estudo.

\section{Mudanças na LDB a partir da lei 13.415/2017}


A lei n. 13.415/2017, promulgada em fevereiro de $2017^{4}$, instituiu a Política de Fomento à Implementação de Escolas de Ensino Médio em Tempo Integral, ficando conhecida como Reforma do Ensino Médio. Nossa investigação se dirige ao conteúdo da nova legislação, especialmente as alterações provocadas nos artigos 24, 35 e 36 da Lei de Diretrizes e Bases da Educação da Educação Nacional (LDB) e aos argumentos que enaltecem a relevância da reforma na esfera de seus proponentes e defensores.

O secretário de Educação Básica do Ministério da Educação, Rossieli Soares da Silva, afirmou que a reforma "é fruto do amplo debate acumulado no País nas últimas décadas, o que permitiu ao governo acelerá-la”, e também disse que "não havia mais condições de termos perspectivas de futuro para os jovens do nosso país, caso não realizássemos esta reforma" (2017, p. 277-278). Frequentemente veicula-se nos meios que defendem o novo formato do ensino médio que o objetivo é tornar a escola de nível médio mais atraente e articulada com mundo em que se vive. Uma matéria veiculada no Jornal do Senado, produzida por Tércio Torres (21/07/2017), tem como título "Reforma promete ensino médio mais atraente". Segundo a matéria, as mudanças possibilitariam ao aluno escolher parte das disciplinas de acordo com sua aptidão profissional. Isso significa que as disciplinas continuarão segmentadas, havendo uma parte obrigatória e outra optativa, além do aumento da carga horária e da implementação do ensino médio integral. A matéria explica que o currículo será definido a partir da "Base Nacional Comum Curricular (BNCC) e de itinerários formativos' correspondentes a quatro áreas do conhecimento: linguagens e suas tecnologias; matemática e suas tecnologias; ciências da natureza e suas tecnologias; ciências humanas e sociais aplicadas". Outro elemento destacado na matéria é a fala do senador Pedro Chaves (PSC - MS), que foi relator da reforma no Senado. Segundo chaves "a educação é uma fonte de desenvolvimento econômico e social". Duas grandes questões emergem dos

\footnotetext{
${ }^{4}$ A primeira versão daquilo que seria a lei 13.415/2017, foi a Medida Provisória $n^{\circ}$ 746/2016, do Governo Federal do Brasil, que em caráter de urgência estabeleceu mudanças em vários aspectos do ensino médio. A maiorias das mudanças propostas pela MP, foram referendadas na aprovação da lei 13.415/2017.
} 
elementos destacados pelos defensores das mudanças, por um lado a ineficiência do ensino médio atual e por outro, a falta de flexibilidade, ou currículo rígido que torna as aulas desinteressantes.

A lei instituiu mudanças no Art. 24, Inciso VII, $\S 1^{\circ}$ da (LDB), que estipula a carga horária mínima anual. A nova redação do artigo ficou assim:

A carga horária mínima anual de que trata o inciso I do caput deverá ser ampliada de forma progressiva, no ensino médio, para mil e quatrocentas horas, devendo os sistemas de ensino oferecer, no prazo máximo de cinco anos, pelo menos mil horas anuais de carga horária, a partir de 2 de março de 2017 (BRASIL, 2017)

O Art. 36 estabelece:

O currículo do ensino médio será composto pela Base Nacional Comum Curricular e por itinerários formativos, que deverão ser organizados por meio da oferta de diferentes arranjos curriculares, conforme a relevância para o contexto local e a possibilidade dos sistemas de ensino, a saber:

I - linguagens e suas tecnologias;

II - matemática e suas tecnologias;

III - ciências da natureza e suas tecnologias;

IV - ciências humanas e sociais aplicadas;

V - formação técnica e profissional. (BRASIL, 2017).

O inciso IV agora denominado "ciências humanas e suas tecnologias" possuía a seguinte redação: "serão incluídas a Filosofia e a Sociologia como disciplinas obrigatórias em todas as séries do ensino médio"5. Esse tópico deixa de existir e ambas as disciplinas deixaram de ser obrigatórias.

No Art. 35-A consta que:

\footnotetext{
${ }^{5}$ Editado pela lei $\mathrm{n}^{\circ} 11.684$, de 2008.
} 
A Base Nacional Comum Curricular definirá direitos e objetivos de aprendizagem do ensino médio, conforme diretrizes do Conselho Nacional de Educação[...].

$[\ldots]$

$\S 2^{\circ}$ A Base Nacional Comum Curricular referente ao ensino médio incluirá obrigatoriamente estudos e práticas de educação física, arte, sociologia e filosofia.

$\S 3^{\circ} \mathrm{O}$ ensino da língua portuguesa e da matemática será obrigatório nos três anos do ensino médio, [...].

$\S 4^{\circ}$ Os currículos do ensino médio incluirão, obrigatoriamente, o estudo da língua inglesa e poderão ofertar outras línguas estrangeiras, em caráter optativo, [...]. (BRASIL, 2017).

Nota-se que o $\S 2^{\circ}$ estipula a obrigatoriedade de filosofia, sociologia, arte e educação física no âmbito de estudos e práticas, não havendo em nenhum outro dispositivo assegurada a obrigatoriedade enquanto disciplinas específicas. $\mathrm{O} \quad \S 3^{\circ}$ estipula a obrigatoriedade da língua portuguesa e matemática nos três anos do ensino médio. Uma flexibilização maior das humanidades e uma confirmação das linguagens e exatas são notórias nesses parágrafos da nova legislação. Outro aspecto acrescido foi o $\S 6^{\circ}$.

$\S 6^{\circ}$ A União estabelecerá os padrões de desempenho esperados para o ensino médio, que serão referência nos processos nacionais de avaliação, a partir da Base Nacional Comum Curricular (BRASIL, 2017).

O parágrafo acima citado, reafirma a padronização das avaliações de desempenho que terão critérios a nível nacional, a partir da Base Comum Curricular. Apesar da recente aprovação da BNCC para o ensino fundamental, e da proposta em discussão para o ensino médio, muitas 
dimensões estão bastante nebulosas com relação as mudanças que estão sendo realizadas. A legislação passa a especificar também a necessidade de articular a escola com o mercado de trabalho, ofertando maior formação técnica e profissional, com professores podendo atuar pelo notório saber (Art. 36, § 11). Cabe ressaltar, que os elementos apresentados neste tópico, são os que mais receberam holofotes nas matérias jornalísticas e produções aliadas a reforma do ensino médio.

\section{A educação para o lucro como proposta do "novo ensino médio"}

Anteriormente, destacamos embasados na obra de Martha Nussbaun, que a educação está confrontada perante enormes desafios e que duas tendências procuram oferecer respostas a eles: uma pautada por objetivos voltados primeiramente ao desenvolvimento da cidadania pelas humanidades e, outra, focada primordialmente na garantia do progresso econômico, ou lucratividade. Os elementos citados no tópico anterior (a. ampla discussão; b. aumento da carga horária; c. organização curricular; d. mercado de trabalho) necessitam de uma análise mais profunda, em vista de apontar limitações e contradições.

Moura e Lima Filho (2017, p. 119) contrapõem o discurso do Ministério da Educação de que a reforma foi amplamente discutida, pois ao baixar medida provisória de caráter urgente "suprime o debate social e a manifestação democrática". Para os autores,

Os principais argumentos justificadores são nitidamente de caráter ideológico e viés neoliberal, apoiando-se sobretudo em três aspectos: crítica ao assim denominado "currículo rígido" atual e, em consequência, na necessidade premente de sua substituição por outro "flexível, enxuto e dinâmico"; na proposição do estabelecimento de itinerários formativos diferenciados no EM, de forma a "valorizar a escolha" dos estudantes para aquele itinerário que mais os satisfaça, concedendo-lhes o chamado "protagonismo 
juvenil"; no estabelecimento da "escola de tempo integral" (MOURA; LIMA FILHO, 2017, p. 119)

A solução oferecida pela nova proposta para superar a "crise do ensino médio" está na reorganização curricular, inclusive no progressivo acréscimo de horas anuais, contudo, negligencia-se algo que é central e não foi abordado pela nova lei que é falta de estrutura para garantir o funcionamento do novo formato, especialmente nas escolas públicas do país. A ausência de instalações adequadas, laboratórios, bibliotecas e outros espaços para atividades esportivas, artístico-culturais, a falta de professores, de planos de carreira e de formação, além de salários dignos e locais de trabalho adequados foram completamente ignorados, tornando a proposta logo de saída altamente contraditória. Torna-se impossível a “realização dos proclamados protagonismos juvenil e flexibilidade, pois essas precárias condições, na grande maioria das escolas, demandam amplos, vultosos e imprescindíveis investimentos" (MOURA; LIMA FILHO, 2017, p. 120).

A reforma flexibiliza nos currículos algumas disciplinas como arte, educação física, filosofia e sociologia diluindo-as nos chamados itinerários formativos, que por sua vez não são todos de oferta obrigatória. Sobre este ponto, Nussbaum (2015, p. 23-24), alerta que "no mundo inteiro os cursos de artes e humanidades estão sendo eliminados de todos os níveis curriculares, em favor do desenvolvimento dos cursos técnicos". Além disso, “os educadores que defendem o crescimento econômico fazem campanha contra a inclusão das humanidades e das artes”. A lei também afirma que questões básicas serão garantidas, como a obrigatoriedade dos estudos em língua portuguesa e matemática (Art. 35-A, $\S 3^{\circ}$ ). Se analisarmos na ótica do pensamento de Nussbaum, a reforma, ao destacar apenas a obrigatoriedade de português e matemática, apresenta-se como retrógrada, muito parecida ao que a filósofa denomina de "modelo antigo de desenvolvimento", que ignora noções básicas para o desenvolvimento humano integral e 
multidimensional, pois "a educação voltada para o crescimento econômico exige competências básicas, que a pessoa seja alfabetizada e tenha noções básicas de aritmética. Também precisa que algumas pessoas tenham conhecimentos mais avançados sobre informática e tecnologia (NUSSBAUM, 2015 , p. 20). Ao fragilizar a pertinência das artes e das humanidades nos currículos, a reforma abre mão de competências básicas essenciais para o fortalecimento da própria democracia, da formação de cidadãos autênticos e reflexivos, além da importância de superar desigualdades distributivas.

Se pudéssemos contabilizar as promessas que recebem maior destaque na reforma do ensino médio e na nova Base Nacional Comum Curricular (BNCC), não seria difícil perceber que a intenção de conectar o ensino médio ao mercado de trabalho estaria em larga vantagem. A ideia de criar um caminho formativo diferente para alguns estudantes, negligenciando uma formação ampla e comum a todos, não é nova no Brasil. Foi amplamente implementada durante a ditadura militar, com a Lei ${ }^{\circ}$ 5.692/1971 e o governo Fernando Henrique Cardoso, com o Decreto $\mathrm{n}^{\circ}$ 2.208/1997. Cunha (2017), salienta que essa ação política tem como pano de fundo a contenção da inserção em massa de estudantes secundaristas ao ensino superior. Sobretudo, porque este apresenta-se em crise. O que no passado solucionou a falta de vagas no ensino superior foram as instituições privadas, que atingiram o apogeu e agora encontram-se, cada vez mais, fechando suas portas. Desse modo, para destinar parte dos jovens estudantes do ensino médio direto para o mercado de trabalho, enquanto outros se preparam para o acesso ao ensino superior, é necessária uma mudança na estrutura curricular do ensino médio.

Diferentemente da ideia de ensino médio integrador, dos governos Lula e Dilma, onde o estudante cursava o ensino médio regular e no turno oposto fazia o ensino técnico profissionalizante, os alunos que optarem em realizar o percurso formativo baseado no ensino técnico estarão sendo preparados para o mercado de trabalho, sendo muito difícil que, futuramente, consigam ingressar no ensino superior. Enquanto isso, outros 
se preparam para as provas que dão acesso as grandes universidades. Essa medida de contenção, como afirmamos anteriormente, não é nova. Como afirma Cunha (2017, p. 379):

Não se trata de invenção de ministro improvisado. Trata-se, isto sim, da reedição da política educacional discriminadora do período Fernando Henrique Cardoso, quando Maria Helena Guimarães de Castro ocupou a presidência do Instituto Nacional de Estudos e Pesquisas Educacionais durante toda sua gestão, após dirigir secretarias nos governos paulistas de José Serra e Geraldo Alkmin. Ela retornou ao Ministério da Educação no governo Temer, agora como secretária geral. A concepção da Medida Provisória $n^{0} 746 / 2016$ é de sua autoria, evidenciada na separação entre o Ensino Técnico e o Ensino Médio, apartação dissimulada nos itinerários formativos específicos - quatro propedêuticos e um terminal. Retorna, assim, a antiga concepção do Ensino Médio como preparação para o Ensino Superior para uns, e formação para o trabalho para outros.

No entendimento de Motta e Frigotto (2017), os alvos dessa reforma são alunos das classes mais baixas da sociedade, porque a grande maioria dos estudantes de ensino fundamental e médio encontram-se nas escolas públicas. Diante das críticas apresentadas por estes autores, permanece a questão com relação aos verdadeiros interesses por trás da reforma do ensino médio, haja vista, que pode tornar-se propagadora de crescentes desigualdades.

Seguindo a lógica dos defensores do novo ensino médio, um percurso formativo profissionalizante levaria um estudante a ocupar um lugar no mercado de trabalho, que exige inúmeros níveis de formação, de modo que ele possa melhorar de vida quando adulto. No entanto, mesmo que os jovens disponham de uma formação técnica, isso não garante que ele terá espaço no mercado de trabalho. 
Ainda que esses jovens vençam o gargalo da passagem do Ensino Fundamental para o Ensino Médio e concluam o Ensino Médio profissional, passam a compor a amarga estatística da maior taxa de desemprego. A falácia de estimular o Ensino Médio para qualificar para o trabalho depara-se com a falta de emprego no mercado de trabalho para a quase totalidade desses jovens (MOTTA; FRIGOTO, 2017, p. 362).

Não temos dúvida que uma economia sólida e uma cultura empresarial próspera são fatores determinantes para os interesses nacionais de cada democracia. Nussbaum (2015, p. 11) na medida em que desenvolve sua argumentação sobre a necessidade das humanidades para o fortalecimento da democracia, afirma que "o interesse econômico também exige que recorramos às humanidades e às artes a fim de promover um ambiente administrativo responsável e cauteloso e uma cultura de inovação criativa”. Educar para a democracia e cidadania supõe uma formação ampla, integral e reflexiva. Abreviar o processo, retirar dos currículos a importância das artes e humanidades leva a riscos sérios para a própria democracia, visto que a educação técnica por si só, não poderá dar conta da formação integral do educando.

\section{Considerações finais}

Amparados em Nussbaum (2015, p. 14) afirmamos que a nova legislação falha por tentar atrelar os propósitos educacionais apenas à lucratividade, esquecendo a igualdade distributiva e social, os pré-requisitos para uma democracia estável, a qualidade das relações raciais e de gênero, enfim, outras dimensões que não estão diretamente incluídas ao crescimento econômico do país. Destacamos também que a educação não pode ser empreendida somente como útil para a cidadania, ela também prepara para o mercado de trabalho, algo amplamente necessário. Contudo, devemos ter cuidado, pois o progresso econômico não significa necessariamente a 
garantia da democracia, do acesso à educação de qualidade, saúde pública, superação das desigualdades.

Se ignoradas as competências ligadas as humanidades, a educação básica continuará padecendo no que tange pensar uma educação para a democracia, para a vida reflexiva e também para a dimensão econômica, pois é um ponto fundamental para a superação de problemas globais que levam a vida humana à degradação em vários sentidos. O problema apontado no trabalho reside na ideia de que a reforma do ensino médio reforça uma extremidade, que é a primazia da educação voltada para o lucro, ignorando a pertinência da formação reflexiva, da formação de sujeitos autônomos e da busca pela alteridade. Poderemos ter seriamente comprometidos os três pilares defendidos nesse estudo, amparado e Nussbaum: a pedagogia socrática (formação de cidadãos autônomos e reflexivos), a busca por uma cidadania do mundo (olhar global) e o exercício imaginativo e criativo, que por sua vez, dialogam intensamente com o ideal de formação humana (bildung). Em geral "reforma" é para tornar algo melhor, entretanto, com base em nossa exposição, não parece ser essa a realidade do "novo ensino médio".

\section{Referências}

BRASIL. Lei n. 13.415, de 16 de fevereiro de 2017. Altera a Lei n. 9.394, de 20 de dezembro de 1996. Diário Oficial [da]República Federativa do Brasil, Brasília, 2017. Disponível em: www.planalto.gov.br. Acesso em 20/11/2017.

CUNHA, Luiz Antônio. Ensino médio: atalho para o passado. Educação $e$ Sociedade, Campinas, v. 38, n. 139, p. 373-384, Abr.-Jun. de 2017. Disponível em: http://www.scielo.br/pdf/es/v38n139/1678-4626-es-38-139-00373.pdf. Acesso em Out. de 2017.

DALBOSCO, Cláudio Almir. Kant \& a Educação. Belo Horizonte: Autêntica, 2011.

Educação Superior e os Desafios da Formação para a Cidadania Democrática. Avaliação, Campinas; Sorocaba, v. 20, n. 1, p. 123-142, mar. de 2015.

FLICKINGER, Hans-Georg. A Dinâmica do Conceito de Formação (Bildung) na atualidade. In: Sobre Filosofia e Educação: racionalidade, diversidade e formação pedagógica. Passo Fundo: Universidade de Passo Fundo, 2009. p. 64-79. 
FRIGOTTO, G; MOTTA, V. C. (2017). O por quê da urgência da reforma do ensino médio? Medida provisória n ${ }^{\circ} 746 / 2016$ (lei no 13415/2017). Educação \& sociedade. Campinas, v. 38, nº 139 , p. 355-372, abr-jun, 2017.

MOURA, Dante Henrique; LIMA FILHO, Domingos Leite. A reforma do ensino médio: Regressão de direitos sociais. Retratos da Escola, v. 11, n. 20, p. 109-129, 2017.

NUSSBAUM, Martha C. Educação e Justiça Social. Trad. Graça Lami. Portugal: Edições Pedago, 2014.

El cultivo de la humanidad. Trad. Juana Pailaya. Barcelona: Ediciones Paidós Ibérica, 2005.

. Sem fins lucrativos: por que a democracia precisa das humanidades. Trad. Fernando Santos. São Paulo: Editora WMF Martins Fontes, 2015.

Recebido em outubro de 2018.

Aprovado em maio de 2019. 